\title{
VIDEO-ASSISTED SURGICAL MANAGEMENT OF ACHALASIA OF THE ESOPHAGUS
}

Robert J. Wiechmann, MD

Mark K. Ferguson, MD

Keith S. Naunheim, MD

Steven R. Hazelrigg, $\mathrm{MD}^{\mathrm{d}}$

Michael J. Mack, MD

Ronald J. Aronoff, MD

Robert J. Weyant, DMD, DrPH

Tibetha Santucci, RN ${ }^{\mathrm{a}}$

Robin Macherey, $\mathrm{RN}^{\mathrm{a}}$

Rodney J. Landreneau, MD
Purpose: Video-assisted surgical approaches to esophageal achalasia continue to be explored by many surgeons involved in the management of this motor disorder. We report our experience with thoracoscopic and laparoscopic esophagomyotomy to more clearly define the efficacy and safety of these approaches. Patients: Over 73 months, 58 patients with achalasia underwent thoracoscopic myotomy $(n=19)$ alone or laparoscopic myotomy $(n=39)$ with partial fundoplication (anterior $=15$; posterior $=24$ ). Mean age was 47.2 years and average length of symptoms was 60 months. Primary symptoms were as follows: dysphagia, 100\%; pulmonary abnormalities, 22\%; weight loss; $47 \%$, and pain, $45 \%$. Mean esophageal diameter was $6 \mathrm{~cm}$ and tortuosity was present in $16 \%$ (9/58) of patients. Prior management consisted of dilation $(n=47)$, botulinum toxin injection $(n=8)$, and prior myotomy $(n=1)$. Methods: In the operating room all patients underwent endoscopic examination and evacuation of retained esophageal contents. The esophagomyotomy was extended $4 \mathrm{~cm}$ superiorly and inferiorly to $1 \mathrm{~cm}$ beyond the lower esophageal sphincter. Thoracoscopic and laparoscopic procedures were completed in all patients without conversion to an open operation. Mean operative time was 183 minutes $( \pm 58.1)$ and hospital stay averaged 2.3 days $( \pm 0.8)$. There was no operative mortality. The 1 operative complication was a perforation that was identified during the operation and repaired thoracoscopically. Results: Symptoms improved in $97 \%$ of patients. Mean dysphagia scores (range 0-10) decreased from $9.8 \pm 1.6$ before the operation to $2.0 \pm 1.5$ after the operation $(P<.001)$ at a mean follow-up of 6 months. Postoperative reflux symptoms developed in $5 \%$ (1/19) of the thoracoscopy group and $8 \%$ (4/39) of the laparoscopy group. Nine patients have persistent or recurrent dysphagia (16\%). Seven patients have successfully undergone Savary dilation, and 2 required esophagectomy to manage recalcitrant dysphagia. Conclusion: At this intermediate term analysis, video-assisted approaches for management of achalasia are a reasonable alternative to extended medical therapy or open operations. (J Thorac Cardiovasc Surg 1999;118: 916-23)
$P^{n}$ neumatic dilation and surgical myotomy remain standard management alternatives for improving esophageal emptying by reducing distal esophageal resistance in patients with achalasia. The extramucosal myotomy described by Heller ${ }^{1}$ and modified by

From Allegheny University Hospitals, Allegheny General, Pittsburgh, $\mathrm{Pa}^{\mathrm{a}}$; University of Chicago, Chicago, Ill ${ }^{\mathrm{b}}$; St Louis University, St Louis, Moc; Southern Illinois University, Springfield, Ill Medical Center Dallas, Dallas, Tex ${ }^{\mathrm{e}}$; and the University of Pittsburgh, Pittsburgh, Pa. ${ }^{\mathrm{f}}$

Read at the Seventy-eighth Annual Meeting of The American Association for Thoracic Surgery, Boston, Mass, May 3-6, 1998.
Zaaijer $^{2}$ remains the operation of choice in the treatment of achalasia. Questions remain regarding the most appropriate surgical approach and the necessity for inclusion of an antireflux procedure in patients undergoing myotomy. ${ }^{3-6}$ With the advent of laparoscopic and

Received for publication May 8, 1998; revisions requested June 30, 1998; revisions received July 8, 1999; accepted for publication July 19, 1999.

Address for reprints: Rodney J. Landreneau, MD, Allegheny University Hospitals, Allegheny General Thoracic Surgery, O2 Level South Tower, 320 East North Ave, Pittsburgh, PA 15212-4772.

Copyright (C) 1999 by Mosby, Inc.

$0022-5223 / 99 \$ 8.00+0 \quad \mathbf{1 2 / 6 / 1 0 1 5 5 9}$ 


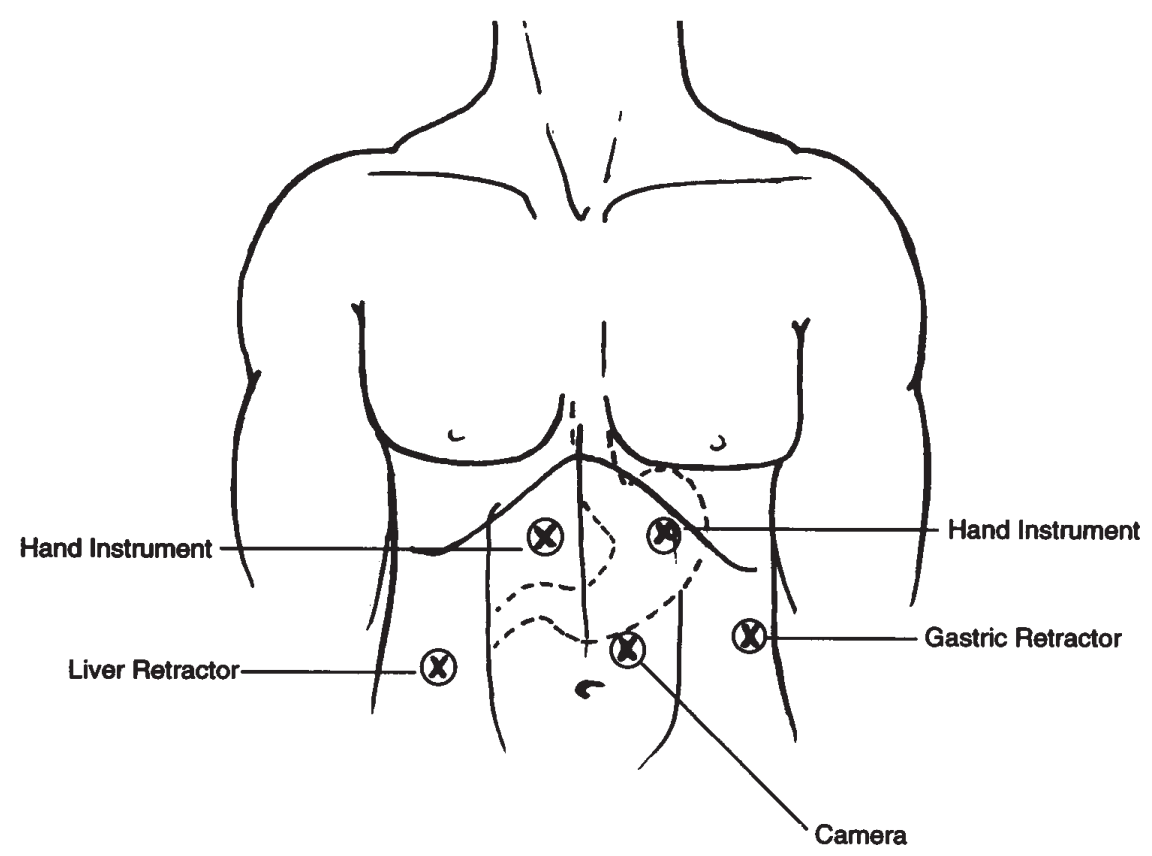

Fig 1. Line drawing of sites of abdominal trocar access.

minimally invasive thoracic surgical techniques and with the increasing acceptance of laparoscopic antireflux procedures, we explored the utility of these minimally invasive surgical approaches in the treatment of esophageal achalasia.

\section{Patients and methods}

Patient profile. Over a 73-month period between December 1991 and January 1998, 58 patients with esophageal achalasia underwent minimally invasive esophagomyotomy. During this period, open myotomies were performed on 17 patients. The mean age of the 58 patients was 47.2 years and there were 32 women and 26 men. The clinical evaluation consisted of a history and physical examination, barium esophagogram, esophagoscopy, and esophageal manometry. Prolonged esophageal $\mathrm{pH}$ testing to rule out associated gastroesophageal reflux disease was only rarely performed because of the inherent lack of indication/utility associated with this technique in the preoperative assessment of esophageal achalasia. Nineteen patients underwent thoracoscopic esophagomyotomy and 39 patients underwent a laparoscopic esophagomyotomy and a partial fundoplication procedure. The decision to use either a laparoscopic or thoracoscopic approach was based on the surgeon's preference for and experience with either the thoracoscopic or laparoscopic techniques. Of the antireflux procedures used in conjunction with the laparoscopic esophagomyotomies, an anterior partial fundoplication (Dor) was performed in 15 patients and a posterior partial fundoplication (Toupet) in 24 patients. ${ }^{7,8}$

Clinical features. The diagnosis of achalasia was made by assessing the combined results of the patient's clinical history, esophagogastroduodenoscopy, barium esophagogram, and esophageal manometry. All 58 patients had preoperative dysphagia and $45(78 \%)$ of the 58 patients described important regurgitation symptoms. Weight loss greater than 10 pounds was noted in 29 patients (47\%). Respiratory complications were also common (aspiration, recurrent pneumonia, bronchitis), occurring in 13 patients $(22 \%)$. Postprandial chest pain was an important primary symptom described by 21 patients $(36 \%)$, and 35 patients $(60 \%)$ had a sensation of heartburn. Interestingly, this heartburn sensation was poorly relieved with antacid or antisecretory therapy. The average duration of symptoms was $59.9 \pm 56.5$ months with a range of 3 to 240 months. Barium esophagograms demonstrated an average esophageal body diameter of $6 \mathrm{~cm}$, and important tortuosity in the body of the esophagus was noted in $9(16 \%)$ of the 58 patients. Manometric studies demonstrated an average lower esophageal sphincter pressure of $31.5 \pm 14.9 \mathrm{~mm}$ $\mathrm{Hg}$. A lack of peristaltic contraction and the absence of lower esophageal sphincter relaxation in response to swallowing was uniformly noted. Sixty-six percent of patients had absent or very poor esophageal body contractility identified at esophageal manometric assessment. Forty-seven patients $(81 \%)$ had undergone at least 1 previous pneumatic dilation and 8 patients (14\%) had previously received botulinum toxin administration. One patient had undergone a previous open transthoracic myotomy 12 years earlier.

\section{Surgical approaches}

Laparoscopic approach. After careful induction of general anesthesia particularly aimed at avoiding aspiration, 


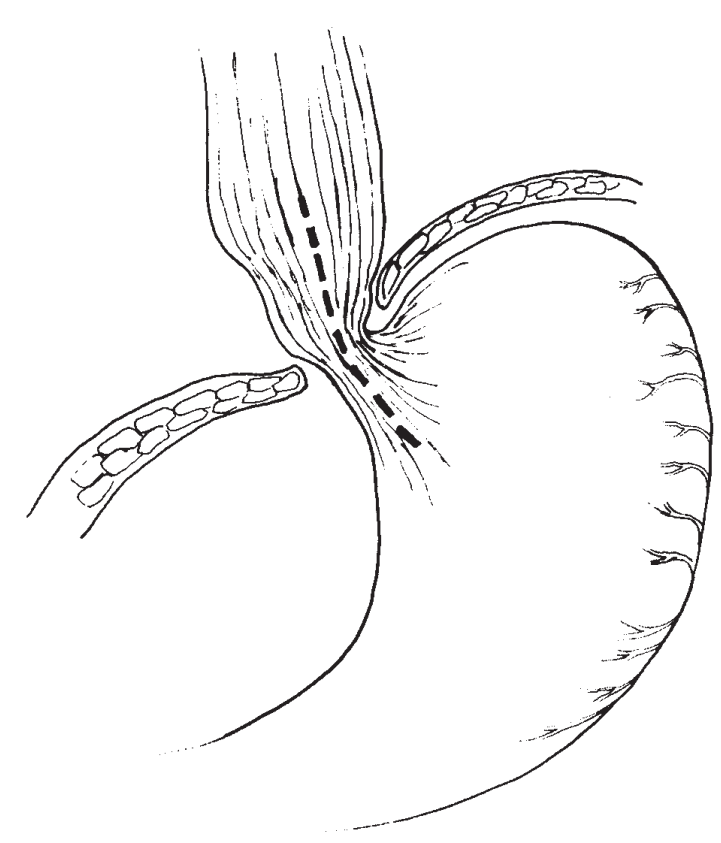

Fig 2. Line drawing of esophageal achalasia and line of proposed esophagomyotomy.

esophagoscopy is performed to remove any residual debris within the esophagus and to inspect the distal esophagus and rule out any other pathologic condition that may be mimicking achalasia (ie, pseudoachalasia caused by a malignant tumor or peptic stricture). The esophagoscope is left in place during the procedure to provide transillumination of the esophageal wall and periodic insufflation during the procedure to ensure the adequacy of the esophagomyotomy.

The trocar access used to accomplish the laparoscopic myotomy is arranged in 2 horizontal rows across the abdomen (Fig 1).

Our approach to the hiatal dissection is nearly the same as that performed through an open laparotomy. The gastric fat pad at the cardia of the stomach is grasped to put tension on the phrenoesophageal membrane over the distal esophagus. The lesser omentum of the gastrohepatic ligament is incised from the phrenoesophageal membrane superiorly to the arcuate ligament inferiorly. This incision exposes the right crural margin and the peritoneal envelope over the distal esophagus. This peritoneum is incised from the arcuate ligament inferiorly to the upper lateral aspect of the right crural arch. The distal esophagus is exposed in the lower part of the mediastinum and further dissection is then carried out in the posterior part of the mediastinum so as to identify and preserve the posterior vagal nerve trunk and to establish the posterior tunnel for subsequent mobilization of the gastric fundus for partial fundoplication. ${ }^{7,8}$

After the dissection of the right aspect of the distal esophagus is completed, the phrenoesophageal membrane over the left aspect of the distal esophagus is divided, including the upper gastrosplenic membranous attachments superior

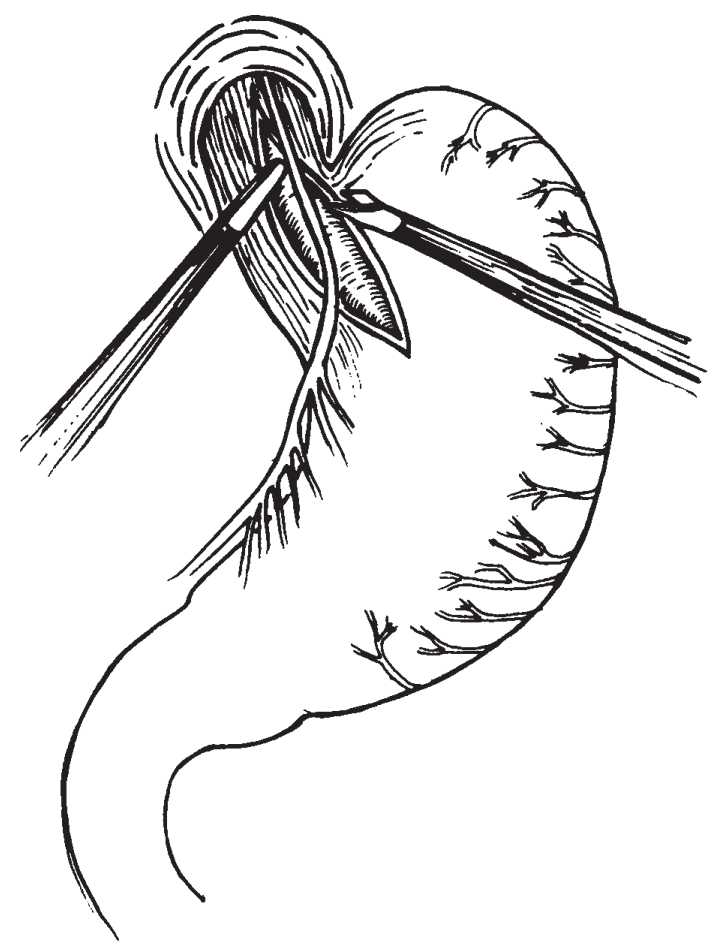

Fig 3. Line drawing of laparoscopic myotomy in progress.

to the short gastric vessels. The left crus and the left lateral aspect of the distal esophagus are thereby exposed. The short gastric vessels along the greater curvature of the stomach are divided with the Harmonic Scalpel device (Ethicon EndoSurgery, Inc, Cincinnati, Ohio) to the level of the left crus. This results in complete mobilization of the gastric fundus.

The esophagoscope is positioned under direct endoscopic vision to the level of the gastroesophageal junction. The esophagoscope is easily identified as the lighted tip transilluminates through the wall of the esophagus. We insufflate the lumen of the esophagus slightly to further assist in delineating the location of the obstruction at the gastroesophageal junction.

The esophagomyotomy is begun on the distal esophagus approximately $2 \mathrm{~cm}$ above the gastroesophageal junction (Figs 2 and 3). Sharp dissection with the endoscopic scissors is augmented with monopolar electrocautery attached to this instrument. Once the mucosal layer is reached, the dissection is carried inferiorly and superiorly on the esophagus within this avascular plane. Periodic insufflation of the esophagoscope ensures that the mucosal layer is intact and that the dissections are proceeding in the proper plane. The esophagomyotomy is extended on the cardia of the stomach until the transverse venous plexus of the cardia is encountered. Simultaneous viewing of the lumen of the esophagus through the esophagoscope allows us to judge when the myotomy has been completed, as the rosette of mucosa that is seen at the distal esophageal obstruction becomes obliterated and free entry of the esophagoscope into the stomach is 
achieved. The myotomy is then widened by teasing the esophageal musculature from the mucosa to ensure that approximately $50 \%$ of the mucosal surface has been unroofed. As mentioned, the proximal extent of the myotomy is to the inferior pulmonary ligament as viewed through the diaphragmatic hiatus.

Once the myotomy has been completed, a modified posterior or anterior partial fundoplication is created (Fig 4).

Thoracoscopic myotomy approach. Our thoracoscopic esophagomyotomy is similar to that described by others. ${ }^{9}$ Contralateral single lung ventilation is accomplished with double-lumen endotracheal intubation to allow for ipsilateral lung collapse and optimal visualization of the esophagus and posterior mediastinal structures. The patient is positioned in the right lateral decubitus position. The basic concepts of thoracoscopic techniques are used. ${ }^{10}$

Intercostal access consists of 4 to 5 sites placed in 2 nearly parallel vertical rows. The anterior row is aligned along the anterior axillary line. The second row of intercostal access is aligned along a midaxillary to slightly posterior axillary line.

The fiberoptic esophagoscope is left in place during the myotomy procedure to assist in elevating the esophagus out of the posterior mediastinal bed and for transillumination and periodic insufflation of the esophageal lumen during the myotomy to ensure the integrity of the mucosa and the adequacy of the myotomy. The myotomy is begun at or slightly above the level of the inferior pulmonary ligament. It is extended on the distal esophagus to beyond the phrenoesophageal membrane so as to enter the coelomic cavity. We extend the esophagomyotomy on the cardia of the stomach to the level of the transverse venous plexus of this region of the stomach. We take care to avoid injury to the more distal oblique muscular sling fibers whose integrity is important in preserving competency of the antireflux mechanism. An antireflux procedure is not included with the myotomy when the thoracoscopic approach is used. ${ }^{9,11,12}$

Follow-up. Routine follow-up evaluation occurred in the early postoperative period (within 30 days of hospital discharge), 6 months after the operation, and then on an annual basis. At the return visits, symptoms were graded with regard to regurgitation, dysphagia, heartburn, chest pain, gas bloat, and diarrhea by means of a symptom analog scale ranging from 0 to 10. In addition, patients were asked to grade their "lifestyle change" and "overall sense of well-being" relative to their preoperative status using a similar 0-to-10 visual ana$\log$ scale. These scores at 1 month, 6 months, and annually were compared with the patients' preoperative symptoms. A postoperative symptom score similar to the system described by Jamieson and Duranceau ${ }^{13}$ was also used to characterize the patients' symptoms before and after repair of achalasia (Table I). In this scoring system, the frequency of symptoms is added to the duration of symptoms and the sum is multiplied by the severity of symptoms. A minimum score of 0 and a maximum score of 32 is possible. Symptom classification is as follows: mild (1-7), moderate (8-15), marked (16-23), and severe (24-32). The percent change from the patients' preoperative scores was calculated. In addition to these symptom

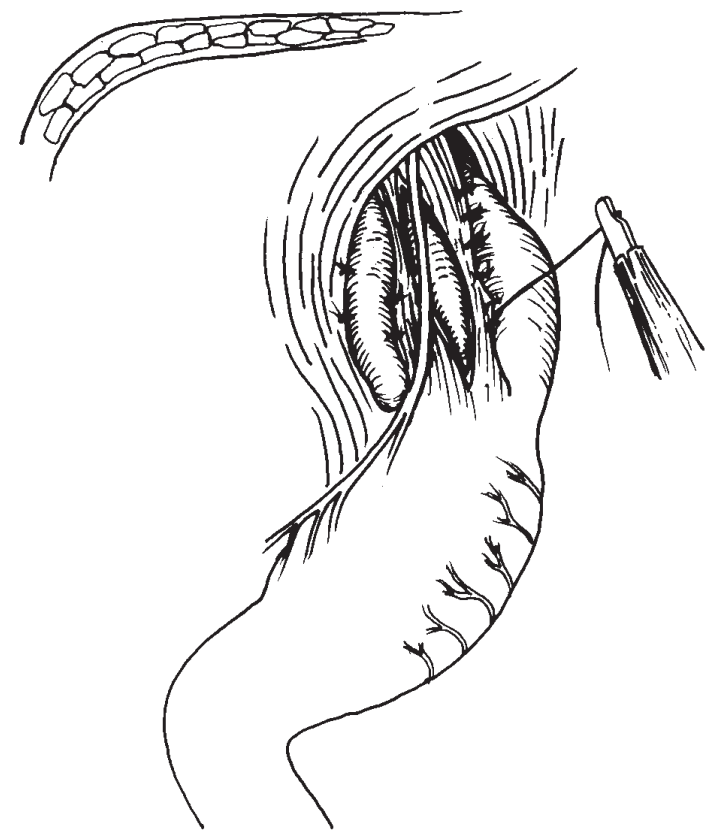

Fig 4. Line drawing of completed Toupet fundoplication.

assessments, follow-up contrast esophagograms were obtained in $30(52 \%)$ of the 58 patients, and follow-up manometry and $\mathrm{pH}$ testing were performed in $10(17 \%)$ of the 58 patients.

Statistical methods. Data were collected by study coordinators, entered into a computerized information management system, and after cleaning and accuracy checks, subjected to analysis. Analysis was conducted with SAS software (SAS Institute, Inc, Cary, NC) on personal computers. The design is an extension of the pretest-posttest design to a preoperative-postoperative situation with 2 time points (eg, preoperative and 6 months, preoperative and 1 year, and preoperative and 2 years). The data in each paired analysis were analyzed by means of a paired $t$ test to determine changes in symptom scores for each symptom among each of the 3 postoperative evaluation periods. In addition, a Bonferroni adjustment was made to control for inflation of type 1 error. A $P$ value of .0056 was set as the adjusted level for statistical significance. Each paired analysis was evaluated for departures from normal before analysis. In all cases, data met minimal requirements for parametric analysis.

\section{Results}

The average operative time was 183.2 minutes (thoracoscopy, $137 \pm 41$ minutes; laparoscopy, $206 \pm 52$ minutes; $P=.04)$. This difference was primarily related to the time required to accomplish the fundoplication procedure after the laparoscopic esophagomyotomy. The average length of postoperative stay was $2.3 \pm$ 0.8 days. The difference in the length of postoperative 
Table I. Achalasia symptom scoring method

\begin{tabular}{|c|c|c|c|c|c|}
\hline & 0 Points & 1 Point & 2 Points & 3 Points & 4 Points \\
\hline I. Frequency & None & $\begin{array}{l}\text { Occasional: Not as often } \\
\text { as once a month }\end{array}$ & $\begin{array}{l}\text { More often than } \\
\text { once a month but } \\
\text { not as often as } \\
\text { once a week }\end{array}$ & $\begin{array}{l}\text { More often than } \\
\text { once a week but } \\
\text { not as often as } \\
\text { once a day }\end{array}$ & Daily \\
\hline II. Duration & No symptoms & Less than 6 months & $\begin{array}{l}\text { More than } 6 \text { months } \\
\text { but less than } 24 \\
\text { months }\end{array}$ & $\begin{array}{l}\text { More than } 24 \\
\text { months but less than } \\
60 \text { months }\end{array}$ & $\begin{array}{l}\text { More than } 60 \\
\text { months }\end{array}$ \\
\hline III. Severity & Absent & $\begin{array}{l}\text { Mild: Nuisance value } \\
\text { only }\end{array}$ & $\begin{array}{l}\text { Moderate: Spoils } \\
\text { enjoyment of life }\end{array}$ & $\begin{array}{l}\text { Marked: Interferes with } \\
\text { living a normal life }\end{array}$ & $\begin{array}{l}\text { Severe: Worst thing } \\
\text { ever experienced }\end{array}$ \\
\hline
\end{tabular}

Calculations: Add frequency to duration and multiply by severity: minimum score $=0$; maximum score $=32$. (From Jamieson GG, Duranceau AC. The investigation and classification of reflux disease. In: Jamieson GG, editor. Surgery of the oesophagus. New York: Churchill Livingstone; 1988. p. 201.)

Table II. Mean change in symptoms between baseline and 6 months, 1 year, and 2 years

\begin{tabular}{|c|c|c|c|c|c|c|c|c|c|}
\hline & \multicolumn{3}{|c|}{ Baseline and 6 months } & \multicolumn{3}{|c|}{ Baseline and 1 year } & \multicolumn{3}{|c|}{ Baseline and 2 years } \\
\hline & $\begin{array}{l}\text { Mean } \\
\text { change }\end{array}$ & $\begin{array}{l}\text { No. of } \\
\text { cases }\end{array}$ & $\mathrm{P}$ value & $\begin{array}{c}\text { Mean } \\
\text { change }\end{array}$ & $\begin{array}{l}\text { No. of } \\
\text { cases }\end{array}$ & $\mathrm{P}$ value & $\begin{array}{l}\text { Mean } \\
\text { change }\end{array}$ & $\begin{array}{c}\text { No. of } \\
\text { cases }\end{array}$ & $\mathrm{P}$ value \\
\hline Heartburn & -4.5 & 44 & .0001 & -7.3 & 20 & .0001 & -6.3 & 26 & .0001 \\
\hline Regurgitation & -6.4 & 44 & .0001 & -7.1 & 20 & .0001 & -7.1 & 15 & .0001 \\
\hline Dysphagia & -8.0 & 44 & .0001 & -6.3 & 20 & .0001 & -6.7 & 15 & .0001 \\
\hline Gas bloats & -0.15 & 44 & .73 & -0.89 & 19 & .23 & -0.75 & 16 & .21 \\
\hline Diarrhea & -0.67 & 52 & .002 & -0.69 & 23 & .12 & -1.2 & 22 & .002 \\
\hline Chest pain & -3.6 & 44 & .0001 & -4.9 & 21 & .0001 & -2.2 & 16 & .06 \\
\hline Lifestyle & 0.42 & 57 & .001 & 0.32 & 28 & .35 & 0.76 & 21 & .09 \\
\hline Well-being & 2.3 & 52 & .0001 & 3.0 & 33 & .0001 & 3.6 & 31 & .0001 \\
\hline Score* & -21.8 & 44 & .0001 & -24.2 & 19 & .0001 & -19.1 & 16 & .0001 \\
\hline
\end{tabular}

Observations limited to those individuals evaluated at both time points. In all cases, the second score was subtracted from the baseline (eg, baseline -6 month score). Calculations based on a formula provided in Jamieson GG, Duranceau AC. The investigation and classification of reflux disease. In: Jamieson GG, editor. Surgery of the oesophagus. New York: Churchill Livingstone; 1988. p. 201.

"See Table I.

stay between patients undergoing thoracoscopic or laparoscopic procedures was not statistically significant. Intraoperative esophageal perforation occurred in 1 patient undergoing thoracoscopy. This perforation was repaired thoracoscopically without sequelae. There were no postoperative deaths.

All patients described marked improvement or resolution of their dysphagia symptoms after the operation. Table II shows the symptom score based on a 0-to-10 scale on a variety of symptoms and lifestyle issues associated with achalasia. Chest pain, regurgitation, and dysphagia significantly improved after the operation, and diarrhea and gas bloat were unchanged. Overall sense of well-being and the overall symptom score $^{13}$ were significantly improved after the operation. The changes in symptoms, lifestyle, sense of wellbeing, and overall symptom scores were statistically significant, as noted in Table II. Similarly, these changes were significantly different at various times analyzed postoperatively with dysphagia and regurgita- tion being statistically significant throughout the period of follow-up. According to the symptom score described by Jamieson and Duranceau, ${ }^{13}$ our patients' symptoms at 6 months, 1 year, and 2 years were significantly better than before the operation. Patients also described a significant improvement in their "lifestyles" and believed their overall "sense of wellbeing" was significantly better than before the operation. Six of the 46 patients with preoperative regurgitation had persistent postoperative regurgitation. Three patients had persistent chest pain after the operation.

At the 6-month follow-up point, $30(52 \%)$ of the 58 patients had a postoperative barium esophagogram. The mean esophageal diameter was reduced to $4.6 \pm$ $1.8 \mathrm{~cm}$ from a preoperative value of $6.2 \pm 1.6 \mathrm{~cm}(P=$ $.0001)$. Ten patients had postoperative manometry performed 6 months after the operation. The lower esophageal sphincter pressure had decreased significantly from $31.5 \pm 14.9 \mathrm{~mm} \mathrm{Hg}$ to $13.5 \pm 3.4 \mathrm{~mm} \mathrm{Hg}$. The improvement in preoperative symptoms and radio- 
graphic/manometric findings was similar between the laparoscopy and thoracoscopy groups, although 6 of the 7 patients requiring postoperative esophageal dilation had a thoracoscopic myotomy performed.

Nine $(16 \%)$ of the 58 patients described recurrence of dysphagia during the period of follow-up. Seven of the 9 patients with significant postoperative dysphagia were managed effectively with 1 or multiple bougie dilations (range 1-4). Two patients had severe recurrent dysphagia that was not amenable to dilation therapy. These 2 patients underwent a transhiatal esophagectomy 4 and 7 months after their minimally invasive myotomy.

\section{Comments}

Primary treatment options for esophageal achalasia include pneumatic dilation, botulinum toxin injection, and esophagomyotomy. ${ }^{14-17}$ Although controversy exists regarding the "optimal" choice of initial treatment, many patients will eventually require surgical management of their disease. ${ }^{16,18}$

The excellent intermediate term results, minimal postoperative pain, and the early recovery from the laparoscopic antireflux operation for medically refractory gastroesophageal reflux disease has changed the attitude of many patients and referring physicians regarding the primary surgical management of esophageal disorders, including gastroesophageal reflux disease and paraesophageal hiatal hernias. ${ }^{19-21}$ A similar inclination has arisen regarding the use of minimally invasive thoracic surgical approaches for a wide variety of thoracic surgical problems, including esophageal achalasia. The improvements in the primary symptoms in our patients undergoing either laparoscopic or thoracoscopic approaches for achalasia confirm the findings of other investigators exploring these techniques. ${ }^{22}$ Excellent control of dysphagia symptoms (96\%) was noted in both thoracoscopic/laparoscopic esophagomyotomy cohorts. The results further confirm a favorable outcome with these minimally invasive surgical approaches that compares well against that seen for endoscopic pneumatic balloon therapy.

Despite the excellent initial improvement in dysphagia and symptom scores, 9 patients followed up between 8 and 72 months after the operation required esophageal dilation for symptoms of recurrent dysphagia. Seven of the 9 patients have had sustained improvement in their dysphagia with dilation alone. Two patients have required esophagectomy for recurrent symptoms refractory to intermittent dilation therapy. Late recurrence of dysphagia reinforces the need for long-term follow-up of these patients. ${ }^{14,23}$ The fact that most patients with postoperative dysphagia requiring dilation had undergone a thoracoscopic myotomy may reflect a difficulty in performing an adequate distal myotomy by means of this technique. Only 1 patient who had a laparoscopic myotomy required postoperative dilation for recurrent dysphagia.

Subjective reflux symptoms after these minimally invasive approaches were infrequent, occurring in only 6 $(10 \%)$ of the 58 patients. These acceptable results reflect our approach of routinely performing an antireflux procedure in patients undergoing a laparoscopic procedure and sparing the upper gastric sling fibers and most of the lateral phrenoesophageal attachments when performing thoracoscopic interventions. No difference was noted in postoperative reflux symptoms between patients undergoing thoracoscopic or laparoscopic procedures.

These minimally invasive procedures were primarily used to manage early to moderate disease or uncomplicated achalasia. Both of the patients requiring later esophagectomy in our series had significant esophageal dilatation and esophageal redundancy recognized in the preoperative period. The role of minimally invasive surgical management of patients with megaesophagus is not as yet determined. Patients with advanced achalasia may be better managed with primary esophageal resection.

As these minimally invasive approaches become more accepted in the management of esophageal disorders, the thoracic surgeons disengaged from these approaches may be left out of the management of these conditions with which they had historically been involved. Although the technical demands of these minimally invasive surgical approaches are similar to those of open surgical esophagomyotomy, it appears that these thoracoscopic techniques are a safe and effective alternative to open operations for the management of uncomplicated esophageal achalasia.

\section{REFERENCES}

1. Heller E. Extramukose kerkioplastic beim chronischen Kardiospasmus mit Dilatation des Oesophagus. Mitt Grenzgeb Med Chir 1914;27:141-9.

2. Zaaijer JH. Cardiospasm in the aged. Ann Surg 1923;77:615-7.

3. Bonavina L, Nosadini A, Bardini R, et al. Primary treatment of esophageal achalasia: long-term results of myotomy and Dor fundoplication. Arch Surg 1992;127:222-7.

4. Abid S, Champion G, Richter JE, et al. Treatment of achalasia: the best of both worlds. Am J Gastroenterol 1994;89:979-85.

5. Ancona E, Anselmino M, Zaninotto G, et al. Esophageal achalasia: laparoscopic versus conventional open Heller-Dor operation. Am J Surg 1995;170:265-70.

6. Andreollo NA, Earlam RJ. Heller's myotomy for achalasia: Is an added antireflux procedure necessary? Br J Surg 1987;74:765-9.

7. Guarner D, Degolla R, Fore NM. A new antireflux procedure at the esophago-gastric junction: experimental evaluation. Arch Surg 1965;110:101-6. 
8. Toupet A. Technique d'oesophago-gastroplastic avec phren.-gastropexie applique'e dan la cure radicale des hernies hiateles et cumme complement de l'operatin d'Heller dan les cardiospasmes. Mem Acad Chir 1963;89:384.

9. Pelligrini C, Wetter LA, Patti M, et al. Thoracoscopic esophagomyotomy: initial experience with a new approach for the treatment of achalasia. Ann Surg 1992;216:291-6.

10. Landreneau RJ, Mack MJ, Hazelrigg SR, et al. Video assisted thoracic surgery: basic technical concepts and intercostal approach strategies. Ann Thorac Surg 1992;54:800-7.

11. Ellis FH, Gibb SP, Crozier RE. Esophagomyotomy for achalasia of the esophagus. Ann Surg 1980;192:157-61.

12. Ellis FH, Crozier RE, Watkins E. Operation for esophageal achalasia. J Thorac Cardiovasc Surg 1984;88:344-51.

13. Jamieson GG, Duranceau AC. The investigation and classification of reflux disease. In: Jamieson GG, editor. Surgery of the oesophagus. New York: Churchill Livingstone; 1988. p. 201-11.

14. Okike N, Payne WS, Neufeld DM, et al. Esophagomyotomy versus forceful dilation for achalasia of the esophagus: results in 899 patients. Ann Thorac Surg 1979;28:119-25.

15. Pasricha PJ, Rai R, Ravich WJ, et al. Botulinum toxin for achalasia: long-term outcome and predictors of response. Gastroenterology 1996;110:1410-5.

16. Csendes A, Braghetto I, Henriquez A, et al. Late results of a prospective randomized study comparing forceful dilatation and oesophagomyotomy in patients with achalasia. Gut 1989;30:299304.

17. Little AG, Soriano A, Ferguson MK, et al. Surgical treatment of achalasia: results with esophagomyotomy and Belsey repair. Ann Thorac Surg 1988;45:489-94.

18. Ferguson MD. Achalasia: current evaluation and therapy. Ann Thorac Surg 1991;52:336-42.

19. Naunheim KS, Landreneau RJ, Andrus CH, Ferson PF, Zachary PE, Keenan RJ. Laparoscopic fundoplication: a natural extension for the thoracic surgeon. Ann Thorac Surg 1996;61:1062-5.

20. Landreneau RJ, Wiechmann RJ, Hazelrigg SR, et al. Success of laparoscopic fundoplication for gastroesophageal reflux disease. Ann Thorac Surg 1998;66:1886-93.

21. Wiechmann RJ, McKesey P, Ferguson MK, et al. Experiences with the laparoscopic approach to "giant" paraesophageal herniation. Proceedings of the Society of Thoracic Surgeons Annual Meeting. New Orleans: January 26-28, 1998; p. 66.

22. Raiser F, Perdikis G, Hinder RA, et al. Heller myotomy via minimal-access surgery. Arch Surg 1996;131:593-8.

23. Orringer MB, Stirling MC. Esophageal resection for achalasia: indications and results. Ann Thorac Surg 1989;47:340-6.

\section{Discussion}

Dr Antoon E. M. R. Lerut (Leuven, Belgium). From this presentation it becomes clear that minimally invasive treatment of achalasia is technically feasible with minimal operative and postoperative complications and without postoperative mortality. I therefore fully endorse your conclusions that thoracic surgeons interested in esophageal disease should become familiar with these techniques. I have some remarks on your conclusion of an overall improvement of primary symptoms in up to $97 \%$ of the patients at 6 months' evaluation.

To come to this conclusion you have been using a visual analog scale to score the different symptoms and then incor- porating these scores in the Jamieson-Duranceau scoring system by adding frequency and duration of symptoms. However, a substantial subset of your patients has not yet reached 2 years' follow-up, which means that these patients cannot reach the 3- or 4-point mark in the duration of symptoms score. To a certain extent, this influences the final result in a favorable way. Indeed, at 2 years only a maximum score of 24 points can be reached against a maximum of 32 points before the operation, as the mean duration of symptoms was as much as 60 months. Moreover, as such a scoring system deals with the overall results from the entire group of patients, it acts like a smoke screen disguising the scores of each individual patient, which I think are much more relevant to evaluate. In fact, 6 patients continue to have regurgitation, 5 have symptoms suggesting reflux, and 3 continue to have chest pain. Furthermore, you mentioned 23 patients with postoperative loss of weight, with a mean of $5 \mathrm{~kg}$, and as many as 9 patients (15\%) required subsequent dilations, 2 of whom eventually had an esophagectomy. In my mind the true failure rate of the cardinal symptom, dysphagia, is $15 \%$, illustrating a tendency of gradual degradation of the results over time.

Also troublesome is the lack of objective evaluation. Only $68 \%$ had a preoperative documented manometric diagnosis, and in the postoperative evaluation there were only 10 manometries and $24 \mathrm{pH}$ studies, with no repeat on the results of the latter investigation. Therefore I think your conclusion is overly optimistic. Further careful follow-up is certainly required to evaluate whether this method really matches the results obtained in open operations.

I have 3 questions. First, this is a multi-institutional report dealing with 58 patients spread out over 5 institutions over 70 months. That means mathematically about 2 cases a year by each center. I would like to hear your comments about the problems of learning curves and how to avoid the pitfalls of such learning curves.

Second, what is supposed to be the cause of recurrent dysphagia? Was there any difference between the thoracoscopic and laparoscopic approaches, the Toupet or the Dor antiplatelet procedure, or in patients who had previous pneumatic dilations? Why did you not perform a second myotomy rather than an esophagectomy, unless the esophagectomy was already indicated at the first operation?

Third, did you find any morphologic differences in those patients who had previous pneumatic dilations and/or the number of those dilations? Is the operation more difficult in those patients? In other words, does pneumatic dilation unfavorably affect the indication for minimally invasive approaches? This eventually would be an argument favoring surgery over pneumatic dilation.

Dr Wiechmann. I agree that careful follow-up is certainly necessary in this group of patients. In response to your questions, I think there is a learning curve. In fact, our numbers at all institutions increased significantly with time, and there was clearly a progression of the procedure with time. As to avoiding pitfalls of the learning curve, as we become more experienced with all laparoscopic and thoracoscopic tech- 
niques, then we are able to avoid the pitfalls of this procedure. It is essential to understand the pathophysiology of achalasia and to be accomplished in the open management of this disease process before one begins to use minimally invasive techniques.

Was there a difference in dysphagia between the patients who underwent a thoracoscopic or a laparoscopic approach? We compared the patients who had undergone a thoracoscopic and laparoscopic approach with this question in mind and did not find a significant difference in postoperative dysphagia. There was a slight difference in operative time but no significant difference in efficacy of the procedure. The 2 (13\%) patients who underwent an esophagectomy had rather advanced disease with significant tortuosity and more of a "sink trap esophagus." Our experience with these 2 patients led us to the conclusion that this procedure would be better attempted in patients with uncomplicated achalasia and without significant tortuosity. In fact, 2 patients who had significant tortuosity and underwent a minimally invasive procedure did later require esophagectomy because of failure of the procedure.

Was there a difference in patients who had preoperative dilations? Most of our patients did undergo preoperative dilation, and I do not believe surgery was more difficult in those who had undergone dilation and those that had not. Therefore I do not believe that patients who undergo preoperative dilation should be excluded from undergoing a minimally invasive procedure, nor are their operations significantly more difficult.

\section{Timely}

The Journal of Thoracic and Cardiovascular Surgery delivers the information you need now. Articles usually appear within four months of acceptance. 